\title{
Using the Principles of Neurolanguage Coaching and Brain Friendly Techniques in Foreign Language Teaching in the Inclusive Learning Environment
}

\author{
Tatiana Belova ${ }^{1, *}$
}

\author{
${ }^{1}$ Russian State Specialized Academy of Arts, Moscow, Russia \\ *Corresponding author.Email: Beltatiana11 @ gmail.com
}

\begin{abstract}
The purpose of this article is to describe the practical application of some principles and methods of neurolingvistic coaching and neuroscience in foreign language teaching in the inclusive educational environment. The research is based on the practical experience of foreign language teaching in mixed ability inclusive classes, in which students with visual impairment learn together with healthy peers. It can be useful for educators who work in the inclusive environment as well as for teachers working with multilevel and mixed ability groups. This paper is addressed to teachers who are constantly searching for new approaches in foreign language teaching and want to incorporate some brain friendly techniques in their work.
\end{abstract}

Keywords: Neurolanguage coaching, Neuroscience, Brain, Memory, Inclusion.

\section{INTRODUCTION}

In the modern world the industry of foreign language teaching is developing very quickly and the demand on using new technologies and methods is constantly growing. Very often foreign language becomes an integrated sphere, in which the teacher should not only know the language and the methods of teaching but also know how to use new technologies, online services, know psychological principles of work, be flexible and respond to constant demands from our students. Modern students are not the same as twenty or even ten years ago, they want to achieve concrete results in short time, on the other hand, we can notice the problem of constant cognitive overload and multitasking that often result in stress and decrease of motivation. Therefore, teachers are constantly searching for new approaches that can help students to activate their brain and to reduce stress. That is why recently we can notice the growing interest towards neuroscience and the brain research. Progressive teachers try to incorporate methods of neuroscience in their work that is why the methodology of teaching is gradually changing. It requires deeper knowledge of psychological processes, such as motivation, goal settings, attention, logical thinking and memorization techniques. Teachers working in the inclusive educational environment should be even more professional and understand better the needs and problems of their students as well as their strengths and abilities. Such knowledge enables teachers to increase their effectiveness in the classroom and to gain the trust of their students. On the hother hand we can notice the constant growth of pseudo neuroscience and pseudo courses which offer quick results without any effort. It's the task of the teacher to get informed about new trends in the field of brain research and to select only those methods, which works better in concrete practical situations.

In the previous article "Discovering abilities" [1], we discussed the individual approach in foreign language teaching that can be useful for teachers working in the inclusive classroom. By inclusive classroom we mean the environment where students with visual, physical or hearing disabilities learn together with other students. We stated that one of the main tasks for a teacher is to understand the strengths of our students and to base our teaching methods on them. On the other hand the teacher should understand possible problems that 
may arise during the process of language acquisition in the inclusive classroom.

To continue the idea of the previous article we'd like to go deeper in the question of individualization and to analyze some of the latest trends in foreign language teaching that might be interesting and useful for our students. These are not purely theoretical findings but methods that were applied in real situation of the inclusive language lessons in Russian state specialized academy of arts where I teach Italian language in the inclusive groups for more than fifteen years. Being blind myself I successfully work with mixed ability groups where visually impaired and healthy students learn together. Last year we were asked to move our lessons online, therefore, the previously mentioned questions of individualization, attention, reducing of stress, memorization and brain research appeared even more evident for our work. In this case, we tried to analyze new technologies and principles of language teaching and found the ideas of neurolanguage coaching and brain research very useful and practicably applicable in our case. That is why in this article, I would like to analyze some principles of neurolanguage coaching and brain friendly methods in order to explain how they can be used in mixed ability groups or inclusive educational environment.

\section{COACHING, LANGUAGE COACHING, AND NEUROLANGUAGE COACHING}

In the last decade of the twentieth century coaching became an independent discipline and was used mostly in the field of business. Nowadays The International Coaching Federation defines coaching as 'partnering with clients in a thoughtprovoking and creative process that inspires them to maximize their personal and professional potential'. [2] Thus coaching is about helping students to grow personally and professionally, to become more creative and flexible in difficult situations and to think and analyze their learning path and progress. Thus, coaching is focused on individual approach, personal growth through constant dialogue, setting and correcting goals, finding intrinsic and extrinsic motivation and developing personal learning strategy. Language coaching is focused mainly on the language learned by a student. So language coach can be language teacher that brings to the learning process the principles and the ethic of coaching. Neurolanguage coaching is one of the branches of language coaching that includes the latest research in the field of neuroscience that includes brain friendly conversations, studying attention and memorization techniques. Rackel Paling in her book "Neurolanguage Coaching: Brain friendly language learning" defines neurolanguage coaching as "the efficient and fast transfer of language knowledge with sustainable effects from the Language Coach to the Language Coachee facilitated by brain-based coaching and coaching principles as vehicles" [3]. That means neurolanguage coaching is focused mainly on the methods of acquisition of the language based on modern brain research and the teacher becomes the bridge between scientists and simple learners. The task of the teacher is to select and bring this information in the class.

\section{PRACTICAL APPLICATION}

Even if initially coaching and neurolanguage coaching are meant mostly for individual students, there are several key principles that can be incorporated in academic learning style in order to make learning easier and less stressful.

The first point that comes from neurolanguage coaching is awareness. The better we understand ourselves and the students that we teach, the better the learning process can be. The main task is to analyze our own methods and techniques in order to see what works best for our learning process. After that we can help our students to understand their strengths and abilities through learning the language. Foreign language is important itself and the students should know conversation patterns, grammar rules and vocabulary, but it is even more important to help students to find their own way of learning in order to understand what works best for them. According to the principles of neurolanguage coaching the task of the teacher is not only to deliver the language knowledge but to help students understand themselves so they can use this information throughout the whole life.

The next important principle of neurolanguage coaching is goal setting. Even if our students are not linguists and foreign language is learned as a general academic subject we still may have conversation about language goals. We can do it at our first lecture and ask students to formulate their learning goals, which are usually professional or personal. As it was noticed during our goal setting session nobody noted personal growth, the brain development or improvement of the memory. When we discussed these aspects of learning together, our students were really amazed and willing to know 
more about it because nobody told them previously about this topic. It was clear that it is very important to talk about the process of language acquisition, explain some brain friendly techniques in order to gain trust and get our students motivated. After formulating individual goals, we can focus on our group goals or course objectives. Even if we cannot achieve all learning goals within the framework of an academic subject, we can still focus on them while formulating home tasks or topics. It can be useful to divide learning goals into shorter steps in order to facilitate learning process. After a certain period of time we can revise our goals together in group or individually.

The next important principle that comes from coaching and neurolanguage coaching is motivation. During the first months of study the motivation is usually high. Everything is new for the students. They are curious and want to achieve good results. In language learning process the results are evident, at our first lesson the students learn the first words and phrases in the foreign language, but after one or two months they can talk about themselves, their families and some other simple topics. Later on, we can notice the decrease of motivation. That happens due to several facts. Learners understand that the learning process is not that difficult and they can achieve good results at the exams without attending all the lectures or doing all tasks. They start to understand that besides of the university they can start working or participate in other activities. They are often busy at concert rehearsals and feel tired after them. Lastly, grammar structure and topics become more complicated and the progress is not so evident. The students are often discouraged and the teacher feels that the materials are no longer perceived so well by the students. At this point we can talk about the first language plateau. The best thing the teacher might do about it is to be aware of it and to talk about it beforehand with the students in group or individually when the first symptoms appear. The next thing is to help them individually to cope with this trouble by simple conversation, empathy, active listening techniques and by building a concrete step-by-step plan of learning, which should be constantly controlled and revised if needed. Another method that helps to increase the motivation is to make the progress of students as evident as possible. In this case, any kind of calculations and graphs work best. Even if it is very difficult to measure conversation, we still may calculate the time of speaking or the number of needed words or phrases used by the student and compare it with the previous lessons. Another useful technique is automatic tests or quizzes. The students feel more relaxed when the tests are checked automatically, so they can redo them and get better results. To create such tests we can use Google forms or other test builder. Another method we use in some groups is the student's diary and a point-rating system, in which points are given for various activities, including home tasks and work in the class. Students with major points can have benefits at the exam session. The point-rating system is a flexible tool and can be adapted to different educational needs and learning cases. Apart from giving points the student's diary includes comments, feedback from the teacher and personal recommendations, which is a good way to personalize learning process. Another powerful tool, which is often ignored by academic teachers, is an individual conversation where the student and the teacher discuss current problems, analyze the progress and the difficulties and together find the best solution. Many teachers think that it takes extra time but the effect of the conversation can be surprising.

The next important principle of neurolanguage coaching which differentiates it from any other type of coaching is creating brain friendly atmosphere and presenting brain friendly techniques of learning. Here are some methods and features that could be done.

In any foreign language class there is always a huge amount of information: new vocabulary, grammar structures, phrases, dialogues and texts. It is easy for a student to get frustrated. To create more brain friendly atmosphere the teacher can reduce the stress by giving priority to the information. Explain the students which information is obligatory and which topics are optional. Even if every piece of information is important it is still useful to make choice and give priority. If we do it, we activate long term memory and reduce short term memory load. On the other hand, we facilitate learning process and make the course objectives clearer. The same thing applies to home tasks. When students are given several or at least two options by making choice they feel their responsibility and are more likely to complete the task.

Another important feature is creating relaxed and brain friendly atmosphere of mutual respect and trust in any learning group, especially when we work with mixed ability or inclusive groups. The task of the teacher is to reduce the anxiety and to give students the opportunity to express their ideas 
and feelings without criticism or judgments. Relevant lesson topics and relaxed atmosphere help students feel that they are equal partners despite their learning differences or physical disabilities. To do it, the teacher can include more pair work in the lesson where students with disabilities work together with healthy peers. Usually, students like to talk about themselves and their interests. The teacher should be empathetic and use active listening to react to every meaningful personal statement.

In one of our previous articles, we discussed the importance of building rapport as a particularly harmonious emotional connection between students and the teacher [4]. Rapport is very important for any learning situation, it helps to reduce anxiety which can block the work of the brain and cause frustration. There are many opportunities to build relationship with students both in and outside the classroom. Rapport must be cultivated from the first class all the way to the last lesson and even after. As teachers, we should take advantage of every message in chat, every feedback and comment and every interaction to develop good rapport. These actions will result in the increasing motivation, friendly atmosphere and trust [5]. As we already mentioned, positive feedback is essential to create brain friendly atmosphere of learning. The teacher should give not only language feedback and correct mistakes but it is extremely important to give content feedback, use active listening techniques and react first to the meaning of the message. This way we reduce the stress, create positive attitude towards errors and help students to build self-confidence.

In order to make learning process more interesting and active, the teacher can talk about the learning process itself and explain how our brain works in terms of attention, memorization and logical thinking. The students are willing to know more about themselves and their brain and this information helps to create intrinsic motivation and build trusting relationships between the student and the teacher. It is essential to explain the students the principles of memorization, the importance of spacing repetitions and the forgetting curve of Ebbinghaus. As teachers, we can introduce a new memorization technique at one of our lessons and ask the students to apply it to the new material. At the next lesson, we can discuss what worked best and which techniques are more useful. The teacher should discuss with the students which methods of memorization work best for each individual.
When we learn, our brain constantly forms new connections and associations with previously learned material. The task of the teacher is to activate associative memory and help to form new connections. It is better for a teacher not to give ready made associations but ask the whole group to come with their own ideas, so it would be easier for everyone to recall the needed word or phrase. Try to compare words or to find contractions. It helps to create the link between previously stored and new material. It is important to create positive associations not only with words, but with the whole learning process itself where students feel relaxed and confident. Use games and humour where possible.

One of the things the teacher can do is to think about the learning style of any student. In order to do it, we created a student's diary that was discussed previously in this article. Another very important tool is a special questionnaire that students complete after a certain period of time. In this questionnaire students must not only analyze their progress, they can answer questions about their learning style. They understand better what helps them to memorize and how they prefer the information to be delivered.

As it has been already mentioned, in neurolanguage coaching the grammar is presented in the form of brain friendly conversation when the teacher asks special questions and waits for the answer. In groups students may have different ideas and the process of discovering grammar becomes more involving. The role of the teacher here is not to explain the rules and give direct answers. The presentation may start with the picture, video o story, after that by asking questions the teacher leads to the discovery of a new rule. The next step is to practice newly learned material in conversation. It is better to do it in pairs, so the students can exchange partners and repeat the same information several times without any additional effort. This way we activate the subconscious memorization of needed material.

\section{CONCLUSION}

In conclusion, we should say that the principles of neurolanguage coaching are very close to the modern educational standards. We create an individual approach, use games and humour to motivate our students, talk about learning goals and motivation. On the other hand teachers should be aware of modern brain research and neuroscience in order to include this information into the teaching 
process and select carefully only appropriate methods. Modern teachers should learn more about brain friendly techniques of learning, memorization tools, the principles and the ethics of coaching that help to build confidence with our students especially with those who need particular attention. Teachers should be also aware of pseudo research in order to understand what methods should not be used in teaching. In general, we think that the principles of neurolanguage coaching and neuroscience may be helpful for any progressive foreign language teacher.

\section{AUTHORS' CONTRIBUTIONS}

The author Tatiana Belova searched the appropriate literature, described her personal experience of teaching, drafted the article and revised it critically.

\section{REFERENCES}

[1] T. Belova, Discovering Abilities. An Individual Approach to Foreign Language Teaching in Inclusive Environment, in: Proceedings of the 2016 International Conference on Arts, Design and Contemporary Education, Atlantis Press, 2016, pp. $\quad 1020 \quad-\quad 1027, \quad$ doi: https://doi.org/10.2991/icadce-16.2016.251

[2] R. Paling, The Differences between Language Teaching and Language Coaching. Efficient Language Coaching. URL: http://www.languagecoachingcertification.co $\mathrm{m}$ /differences-language teaching-andlanguage-coaching/

[3] R. Paling, Neurolanguage Coaching: Brain friendly language learning, The Choir Press, Kindle Edition, 146 p.

[4] T. Belova, Blind Teacher in Russia Tips and Experience, in: Proceedings of the 1st International Conference on Arts, Design and Contemporary Education (ICADCE 2015), Atlantis Press, 2015, pp 533 - 537, DOI: https://doi.org/10.2991/icadce-15.2015.127

[5] T. Dyrenforth, Classroom Success Through Rapport-Building, West point. URL: https://www.westpoint.edu/sites/default/files/i nline-

images/centers_research/center_for_teching_e xcellence/PDFs/mtp_project_papers/Dyrenfort h_14.pdf
[6] M. Sprenger, How to Teach So Students Remember, 2nd Edition, Association for Supervision and Curriculum Development, Alexandria, Virginia, USA, 2020, 205 p.

[7] C. Jack, Moving Beyond the Plateau, URL: https://www.professorjackrichards.com/wpcontent/uploads/moving-beyond-theplateau.pdf

[8] T. Gallwey, The Inner Game of Tennis: The Classic Guide to the Mental Side of Peak Performance, New York: Random House., 1997, 122 p.

[9] E. Jensen, Brain-based Learning. Brain Store Inc, 1996. - 373 p.

[10] S. Krashen, T. Terrell, The Natural Approach: Language Acquisition in the Classroom. Oxford: Pergamon Press, 1983, 191 p. 